Brit. J. vener. (1956), 32, 154.

\title{
VENEREAL DISEASE IN AUSTRALIA IN THE POST-WAR DECADE, $1945-55^{*} \dagger$
}

\author{
BY \\ J. COOPER BOOTH \\ Lately Director, Division of Social Hygiene, Department of Public Health, New South Wales, Australia
}

During the post-war decade the control of venereal disease in Australia has followed a pattern somewhat similar to that in other informed countries overseas. Full advantage has been taken of improved methods of treatment and in administrative organization, and results compare favourably with those reported from abroad. In New South Wales the Division of Social Hygiene has, on account of the decline in its administrative activity, given place to a new Division of Epidemiology which has included the diminished activities of the former Division in its wider sphere of activity.

In surveying the position in Australia, and especially in New South Wales, for it is to that State that I have looked for most of my information, it may be well to consider in the first place the legal powers under which action for control of venereal disease is carried out. The several States which comprise the Australian Commonwealth are Sovereign States and each is responsible for its own legislation in regard to venereal disease control. In all States, except South Australia, venereal disease is notifiable, the patient being known by initials or number only. The notifiable diseases are syphilis, gonorrhoea, gleet, gonococcal ophthalmia, chancroid, venereal warts, and venereal granuloma. If a patient, who has been notified, defaults from treatment, his name and address is made known to the Health Department so that necessary action may be taken to "follow up" the defaulter and ensure resumption of treatment. Those who do not cooperate are prosecuted.

In all States, with the exception of New South Wales, any person reasonably suspected to be suffering from a venereal disease may be ordered to attend for a medical examination and, if the order is disregarded, may be arrested and brought for examination. If, however, the suspected person is able to produce evidence of freedom from infection,

* Received for publication March 13, 1956.

t Invited article. or proof that he is already under medical care for venereal disease, no further action is taken. During the last war it was necessary for the Commonwealth Government to introduce special legislation to provide for examination and control of suspects as this power was lacking in New South Wales and, then, in South Australia. This is the only occasion on which the Commonwealth Government has introduced legislation affecting the control of venereal disease in the States. This special legislation ceased to have effect after December, 1946.

Power to investigate alleged sources of infection is an essential part of any scheme for venereal disease control, especially in time of war.

As infected people are obliged to attend for examination and treatment, provision of facilities is necessary. In all States treatment is free at public hospitals and clinics, or the patient may have private treatment at his own expense.

With the advent of modern rapid methods of treatment, and smaller numbers of patients, with practically no waiting for attention, default has declined considerably. In New South Wales there were 158 actions for default during 1954. Most notifications of default come from hospitals and clinics. The private patient is seldom reported by his doctor, though he is legally obliged to do so. It is probable that comparatively few private practitioners comply with legal requirements in regard to notifications of venereal disease, and this must affect, though probably in small degree, the value of any figures put forward as giving a picture of the amount of venereal disease in any State. One can only assess the rise or fall in the amount of venereal disease from figures available from long tested and well established sourcés of notification.

So that infected persons may be aware of their obligations, notices are displayed in public lavatories and pamphlets are issued by the Health Departments. One State also issues a special pamphlet in German. There is now very little Press 
publicity because the urgency of the problem has diminished and little is available in the way of dramatic headline news.

\section{Venereal Disease in the Several States}

New South Wales.-During the war there was a decline in the number of males notified as infected and an increase in the number of females. This was to be expected as the figures were for civilians. In New South Wales in 1944 , in a total of 4,410 notifications, 1,548 were for females. After 1944 the female total began to fall: in 1945 there were 985 females in a total of 4,562 notifications, and in 1946, the first post-war year, there were 829 females in a total of 5,401 notifications. In that year (1946) there were 1,024 notifications of syphilis (532 being $n \in w$ infections) and 4,163 of gonorrhoea. Since 1946 there has been a steady decline in notifications, especially for gonorrhoea, with the exception of 1953 when an increase in gonorrhoea was responsible for a small rise, and in 1955 when an increase in gonorrhoea was responsible for a larger one. The year 1955 with 1,797 total notifications ( 200 females) showed an increase of 390 . In this total 1,398 were for gonorrhoea (an increase of 356), 275 for syphilis (107 being new infections), 112 for venereal warts, two for chancroid, nine for gleet, and one for lymphogranuloma venereum. A comparison of the years 1946 and 1955 gives a difference in the totals of 3,604 (a fall of $66 \cdot 7$ per cent.). Syphilis began to decline noticeably from 1950 onwards and the number of cases of syphilis reported in 1955 is the second lowest recorded (the lowest being in 1954). A more striking picture of the position in New South Wales is seen in a comparison of the rates per 100,000 of population for the years 1946 and 1955 , in 1946 the rate for gonorrhoea being $142 \cdot 3$ and in $1955,40 \cdot 02$,the rate for all types of syphilis for the same years was 35 (new infections 18.1) and $7 \cdot 8$ (new infections $3 \cdot 06$ ) per 100,000.

Queensland.-The report for 1954-55 showed a decline in venereal disease in its total of 701 notifications, which was 39 less than that for the previous year. There were 442 notifications of gonorrhoea ( 88 for females), 35 of chancroid, ninety of venereal warts, five of venereal granuloma, one of syphilis and gonorrhoea, and one of syphilis and venereal warts. Syphilis amounted to 127 cases (35 females), of which 75 were early infections. Queensland's peak year for all venereal diseases was 1942-43 when there were 3,101 notifications, which gave an incidence of 298 per 100,000 of mean population. In $1954-55$ the incidence had dropped to 53 per 100,000 .
Western Australia.-For the year 1955 there were 203 notifications, of which fourteen were for syphilis (five primary and one secondary), 188 for gonorrhoea, and one for venereal granuloma. For the year 1954 there were 212 notifications, of which 21 were for syphilis (three primary and nine secondary), 188 for gonorrhoea, two for chancroid, and one for venereal granuloma. In 1953 there were 235 notifications of which 43 were for syphilis (seventeen primary and nine secondary), 189 for gonorrhoea, one for chancroid, and two for venereal granuloma.

Tasmania.-Very little venereal disease was notified in the year 1953-54. In a total of thirty cases there were 24 of gonorrhoea and six of tertiary syphilis. Of those notified three were females (one gonorrhoea and two syphilis).

South Australia.-In this State venereal disease is not notifiable and the position can only be judged from the attendances at the Royal Adelaide Hospital. This hospital has averaged about one new case of syphilis a month over the past 2 years. Most of the patients came from ships. Gonorrhoea is rare but non-gonococcal urethritis is very common. A syphilitic or gonococcal infection is hardly ever seen at the female investigation clinic where "widgies"* are brought for routine examination. Trichomoniasis is not uncommon among the females examined.

Victoria.-The latest report (1954) shows a continuing decline in the incidence of venereal disease. In 600 notifications 133 were for syphilis (28 females), and 467 for gonorrhoea (31 females). In 1948 , for contrast, there were 2,121 notifications made up of 389 syphilis (119 females) and 1,732 gonorrhoea (199 females).

\section{AREAS OF INFECTION}

The large seaports of Sydney, Melbourne, and Brisbane on the eastern coast of Australia have more venereal disease than anywhere else on the continent. Very little venereal disease is reported outside the capital cities. Occasionally there may be sporadic outbreaks at country centres, but these are soon brought under control. It is probable, however, that more venereal disease is treated in rural areas than is reported.

\footnotetext{
* "Bodgies" and "widgies" are males and females in a group which has evolved in Australia since the last war. The bodgie dresses eccentrically, can be violent, but tends rather towards milk bar and street corner meetings and, at times, a somewhat sultry sexual way of life rather than a criminal one. The widgies, their female followers and companions, also dress eccentrically and have similar tastes. They cannot be classed as prostitutes, though they may indulge in illicit sexual intercourse within the bodgie-widgie group.
} 


\section{SOURCES OF INFECTION}

Infections come chiefly from the amateur or nonprostitute. In war time this group was responsible for over 90 per cent. of infections. The prostitute is responsible for remarkably little infection in any year, but appears to be a spreader of syphilis when that disease appears. The homosexual is at times also a spreader of infection. In Queensland special provision is made for the examination and supervision of prostitutes, and known infections from prostitutes during 1954-55 amounted to only 39 . To guard against spread of infection, prophylactic facilities for males have been available for many years at the Sydney Clinic of the New South Wales Health Department. The centre is open continuously, is free, and is well attended. In 1954 prophylaxis was given to 17,942 males, and 17,682 males attended in 1955. Similar facilities are available at several other centres on the Australian coast. This service helps to keep in touch with any who may have been exposed to infection and is useful for venereal disease control propaganda.

\section{TREATMENT}

Penicillin is in general use for the treatment of both syphilis and gonorrhoea. Procaine penicillin $G$ in oil with 2 per cent. aluminium monostearate (PAM) is the antibiotic most commonly used. For gonorrhoea it is usual to give 300,000 units only. For syphilis 6 million units for primary or secondary conditions and up to 12 million units for later conditions give results which appear to be at least as satisfactory as were arsenical and bismuth injections when in universal use. A few medical practitioners appear unwilling to trust to the use of penicillin alone for syphilis and use arsenical or bismuth injections, or both, as well, submitting the patients to long periods of continuous treatment. The amount of penicillin used by many practitioners still varies greatly and at times appears to be grossly excessive. There is little evidence of undertreatment. It should not be necessary to use any arsenical or bismuth injections for syphilis unless penicillin fails or there is danger to the patient in giving penicillin. Preparations of bismuth for injection, at present provided free under the Commonwealth Pharmaceutical Benefits, are to be deleted from the list of benefits.

\section{TEACHING}

The clinical training of medical students is difficult owing to lack of suitable cases at teaching hospitals. Students see very little venereal disease and it is rare for any to see a primary syphilitic sore. At the Sydney clinic of the Health Department small groups of students from one of the general training hospitals are given facilities for seeing what there is to see in the way of diagnosis and treatment, and a few are at times fortunate enough to be present when a field is being searched for the Trepomema pallidum.

\section{COMMENT}

The position in Australia is, at present, very satisfactory. There has been a steady decline in the amount of venereal disease coming under notice. The old slow methods have gone and with them the overcrowded clinics and the need for provision of beds for the complications once so common and depressing. Gonococcal epididymitis, arthritis, and acute prostatic abscess are very rarely seen. Deepseated gonococcal infection in females, with all its tragic possibilities, has become rare. Nor does one see, except very rarely, the disabling complications of syphilis which so frequently in the past wrecked body and mind. Very little congenital syphilis comes under notice, and the mortality from syphilis is very low. It is some years since a case of gonococcal ophthalmia has been notified in New South Wales, and it is very rare in other States.

Though the venereal disease position has improved so much during the last decade, the change has nothing to do with any improvement in human morals. The pattern of sexual behaviour is much the same, and, because of this, the way is ever open for a return of all the venereal disease problems of the past if the protection of the present is removed. So long as there is a reservoir of infection anywhere, venereal disease has not been wiped out. We owe our comparative success to-day almost entirely to the existence of antibiotics which are capable of speedily controlling disease and rapidly limiting spread of infection. If anything should interfere with the use or the effectiveness of these antibiotics, then conditions would revert to what they were in pre-antibiotic days, unless something at least as efficient became available without delay.

Our chief concern to-day is the provision of treatment for non-gonococcal urethritis, which is responsible for much of the work now carried out at venereal disease clinics.

\section{SUMMARY}

The position in regard to venereal disease in Australia, disclosing a continuing decline in the number of reported infections, is surveyed. Legal powers of control, sources of infection, treatment, and teaching facilities for medical students are considered, and the article closes with a comment on the present state of affairs.

I wish to express my thanks to the Health Departments of the several States for the information made available to me. 